\title{
Neonatal isoerythrolysis in Thoroughbred foals
}

\author{
Do Yeon Kwon', Seong Kyoon $\mathrm{Choi}^{2}$, Young Jae $\mathrm{Cho}^{3}$, Gil Jae $\mathrm{Cho}^{2}$,* \\ ${ }^{1}$ Korea Food \& Drug Administration, Seoul 122-704, Korea \\ ${ }^{2}$ College of Veterinary Medicine and Institute of Equine Medicine, Kyungpook National University, Daegu 702-701, Korea \\ ${ }^{3}$ Jangsu Stud Farm, Korea Racing Authority, Jangsu 597-843, Korea
}

(Accepted: March 10, 2011)

\begin{abstract}
Two 4-day-old Thoroughbred foals with acute clinical signs of depression, elevated pulse and respiratory rates, anemia, and jaundice were referred to the equine hospital of Korea Racing Authority. The foals were seemingly normal at birth, but showed clinical signs such as abnormal behavior, jaundice and anemia suddenly after ingestion of the mare's colostrum, followed by death at 4 days after birth. According to the results of the hematology, serum chemistry analysis, jaundice foal agglutination test, and blood groups test, the foals were diagnosed as neonatal isoerythrolysis (NI) caused by the mare's antibodies. These results suggested that the pregnant mares have a potential for NI.
\end{abstract}

Keywords : blood type, neonatal isoerythrolysis, Thoroughbred foal

\section{Introduction}

Neonatal isoerythrolysis (NI) is known as hemolytic disease of newborn cattle, swine, dogs, and horses. NI is a disease caused by the immune-mediated destruction of red blood cells as a result of the attachment of specific antibodies to cell surface antigens. NI is one of the most serious diseases among newborn foals and is caused when the mare produces antibodies against the foal's red blood cells (RBC). This syndrome can occur when the blood type of the mare is different from that of the stallion and the foal inherits a sensitizing RBC type from the stallion [11].

Unlike humans, the damaging antibodies produced by the mare do not cross to the foal through the placenta during gestation. Instead, they will be ingested by the foal in the mare's colostrum $[5,8]$. The symptoms can occur from 6 to $72 \mathrm{~h}$ after birth. The foal can develop signs of lethargy, elevated pulse and respiration rates, anemia, and jaundice. Recovery may be spontaneous, or the disease may progress to severe anemia and death $[5$, $8,11]$.

Horses have complicated blood types, consisting of 34 blood factors that are grouped in 7 systems (A, C, D, $\mathrm{K}, \mathrm{P}, \mathrm{Q}$ and $\mathrm{U}$ ). Factors within each system are designated with small letters. Of these antigens, the blood factors most commonly associated with NI are Aa and Qa. The $\mathrm{RBC}$ antigens $\mathrm{Pa}, \mathrm{Ab}, \mathrm{Dc}, \mathrm{Db}, \mathrm{Qc}$, and $\mathrm{Ua}$ are less commonly implicated in cases of equine NI [2]. Laboratory confirmation of $\mathrm{NI}$ requires demonstration of antibodies that bind the foal's RBC, including blood groups type, jaundice foal agglutination (JFA), positive direct antiglobulin test (Coomb's test) [6, 12].

The objectives of this study were to identify factors associated with death and to present foal loss due to NI in Thoroughbred (TB) horses in Korea.

\section{Materials and Methods}

\section{Animals}

Two 4-day-old TB foals with acute clinical signs of depression, elevated pulse and respiratory rates, anemia, and jaundice were referred to the equine hospital of Korea Racing Authority. The foals appeared normal at birth, but suddenly showed clinical signs such as abnormal behavior, jaundice and anemia and followed by death 4 days after birth.

Hematology and serum chemistry analysis

From the collected blood samples, hematology and

*Corresponding author

Tel: +82-53-950-5978, Fax: +82-53-950-5955

E-mail: chogj@knu.ac.kr 
serum chemistry were measured for each sample using a standard clinical automatic analyzer (Hitachi 7200; Hitachi High-Tech, Japan).

\section{Jaundice foal agglutination test}

A JFA test was performed by tube agglutination test with the foal's RBC and mare's serum. Serial dilutions of the mare's serum were mixed with one drop of the foals whole blood and centrifuged. If agglutination is present in tube button after inverted each tube, the button does not disperse when the tube was flicked. The positive reactions at dilutions of $1: 16$ or greater were considered to be capable of causing NI in foals [1].

\section{Blood group test}

The RBC of the stallions, brood mares, and foals were tested for blood group antigens using direct haemag- glutination and hemolysis with 24 reagents as described by Stormont et al. [12] and Cho et al. [4]. Phenogrouping of the blood type was analysed on the basis of the determination of antigens on the RBC.

\section{Results}

\section{Hematology and biochemistry}

The results of hematology and biochemistry are shown in Table 1. RBC (1.49 and 3.50), packed cell volume (6.5 and 10.3), and hemoglobin (5.1 and 7.2) values were decreased in the hematology test, although mean corpuscular hemoglobin (34.19 and 35.21) values increased. In the serum biochemistry test, aspartate aminotransferase (984 and 892), total bilirubin (9.5 and 9.9), and gamma glutamyltransferase (42 and 45 ) values were increased. These findings revealed severe anemia,

Table 1. Results of the hematological and biochemical analyses in foals with neonatal isoerythrolysis

\begin{tabular}{lcc}
\hline \hline \multicolumn{1}{c}{ Item } & Affected foal I / II & Reference values (ISIS) \\
\hline White blood cells $\left(\times 10^{3} / \mu \mathrm{L}\right)$ & $41.41 / 35.01$ & $5.40 \sim 14.30$ \\
Red blood cells $\left(\times 10^{6} / \mu \mathrm{L}\right)$ & $1.49 / 3.50$ & $6.80 \sim 12.90$ \\
Packed cell volume $(\%)$ & $6.5 / 10.3$ & $32.0 \sim 53.0$ \\
Hemoglobin $(\mathrm{g} / \mathrm{dL})$ & $5.1 / 7.2$ & $11.0 \sim 19.0$ \\
Mean corpuscular volume $(\mathrm{fl})$ & $43.3 / 48.2$ & $37.0 \sim 58.0$ \\
Mean corpuscular hemoglobin $(\mathrm{pg})$ & $34.19 / 35.21$ & $12.30 \sim 19.90$ \\
Neutrophils $\left(\times 10^{3} / \mu \mathrm{L}\right)$ & $35.02 / 34.30$ & $2.26 \sim 8.50$ \\
Monocytes $\left(\times 10^{3} / \mu \mathrm{L}\right)$ & $1.49 / 1.50$ & $0.10 \sim 1.00$ \\
Sodium $(\mathrm{mEq} / \mathrm{L})$ & $132 / 137$ & $126 \sim 146$ \\
Potassium $(\mathrm{mg} / \mathrm{dL})$ & $5.4 / 5.2$ & $2.5 \sim 5.2$ \\
Creatinine kinase $(\mathrm{U} / \mathrm{L})$ & $720 / 650$ & $120 \sim 470$ \\
Glucose $(\mathrm{mg} / \mathrm{dL})$ & $122 / 120$ & $65 \sim 110$ \\
Aspartate aminotransferase $(\mathrm{U} / \mathrm{L})$ & $984 / 892$ & $175 \sim 340$ \\
Total bilirubin $(\mathrm{mg} / \mathrm{dL})$ & $9.5 / 9.9$ & $0.5 \sim 2.3$ \\
Gamma glutamyltransferase $(\mathrm{U} / \mathrm{L})$ & $42 / 45$ & $5 \sim 24$ \\
Total protein $(\mathrm{g} / \mathrm{dL})$ & $4.7 / 5.0$ & $5.7 \sim 8.0$ \\
\hline
\end{tabular}

Table 2. Results of blood typing and predictable mare's antibodies in this study

\begin{tabular}{cllc}
\hline \hline & & \multicolumn{1}{c}{ Red cell types } & Predictable antibody in mare \\
\hline \multirow{4}{*}{ Case 1 } & Sire 1-1 & Aaf, Ca, Dcgm/dk, Qb & - \\
& Sire 1-2 & Aaf, Ca, Dcegmn/dk, Qb/c & - \\
& Dam & Aaf, Ca, Dcegmn/dk, Qc & Qb \\
& Foal 1 & Aaf, Ca, Decgmn/dk, Qb/c & - \\
\hline \multirow{4}{*}{ Case 2 } & Sire 2-1 & Aaf, Ca, Dcegmn/dk, Qb/c & - \\
& Sire 2-2 & Aaf, Ca, Dcgm/dk, Qb & Dc, Dg, Dm \\
& Dam & Aaf, Ca, Ddk, Qb & - \\
\hline
\end{tabular}


leucopenia and liver failure.

\section{Jaundice foal agglutination and blood groups}

The JFA test which is screen test to detect NI was positive (1:16 or greater) in this study. Red cells types are shown in Table 2. Foal 1 and foal 2 inherit a specific $\mathrm{Qb}$ and Dc, Dg, Dm blood group antigen from the sire, respectively, which are incompatible with the antibodies present in the colostrum of the dam. According to the results of the blood group, two foals were diagnosed as having NI caused by the mare's antibodies, anti-Qb and Dc, respectively.

\section{Discussion}

The TB horse is one breed of light horses enhanced for the purpose of horse racing in the United Kingdom. Korea mainly imported TB horses or Anglo-Arab horses from various countries such as Japan and Australia in the 1970s for horse racing. In a move to achieve improvement in horse breeding and stud management and eventually contribute to the development of the horse racing industry and the livestock industry, Korea began breeding horses in 1980s. Currently, there are around 2,500 mares and 90 stallions in Korea. These horses give birth to more than 1,300 foals every year, and the number of foals are steadily increasing [4].

Hemolytic disease of newborns, also known as NI is a serious condition that, if left untreated, can kill an otherwise healthy newborn foal. It is also the most common cause of jaundice in neonatal foals. It is the most common alloimmune disease in foals that is characterized by hemolytic anemia. NI of foals was caused by an incompatibility of blood types between a mare and her foal. If a foal inherits from its sire a RBC factor (antigen) that the mare lacks, the mare may develop antibodies to that antigen. The foal is clinically normal at birth and ingests it dam's antibody-laden colostrum. The antibodies pass into the blood stream by way of the intestine, and attach to the antigens on the foal's RBC. These target antigens were inherited from the sire. The foal's RBC are destroyed immunologically, resulting in anemia, icterus, and, in some cases, death $[5,7,8,11]$. Other causes of hemolytic disease in neonatal foals included disseminated intravascular coagulation, bacteria-induced hemolysis, and iatrogenic causes associated with an incompatible blood or plasma transfusion [3, 9].
Population studies of red blood cell factors most frequently involved in NI reveal that approximately $14 \%$ of foals have erythrocyte incompatibilities with the dam. Usually, the antibodies are at high titer in mares' sera and colostrum and are specific for the Aa and Qa blood group antigen. Approximately $19 \%$ of TB mares are negative for the Aa or Qa antigen, and $17 \%$ of Standardbred mares are negative for Aa. The prevalence of antibodies against commonly offending antigens is $2 \%$ in Standardbreds and $1 \%$ in TB horses $[1,10]$.

The present study evaluates potential factors, the hematology and serum chemistry analysis, JFA, and blood groups test.

According to the results of the hematology and serum chemistry analysis, JFA, and blood groups test, foals were diagnosed as having NI caused by the mare's antibodies. Once a mare has had an NI foal, however, all future pregnancies are at risk. If a mare has demonstrated serologic evidence of anti-red blood cell antibodies a blood groups test or a JFA test should be performed on the foal immediately post foaling and before nursing to definitively identify any risk of NI. Treatment is best aimed at prevention. Taken together, if the NI is suspected prior to birthing, laboratory confirmation requires demonstration of antibodies that bind the foal's RBC, and the foal should be immediately removed from the mare at birth for 1 3 days and suckled on a safe foster mare, or provided with a commercial milk replacement.

\section{Conclusion}

Two 4-day-old TB foals were seemingly normal at birth, but showed clinical signs such as abnormal behavior, jaundice and anemia suddenly after ingestion of the mare's colostrum, followed by death at 4 days after birth. According to the results of the hematology, serum chemistry analysis, jaundice foal agglutination test, and blood groups test, the foals were diagnosed as NI caused by the mare's antibodies. If the NI is suspected prior to birthing, the foal should be immediately removed from the mare at birth for 1 3 days and suckled on a safe foster mare, or provided with a commercial milk replacement.

\section{Acknowledgments}

This study was supported by the Technology 
Development Program for Agriculture and Forestry (108175-03-1-CG000), Ministry for Agriculture, Forestry and Fisheries, Republic of Korea.

\section{References}

1. Bailey E. Prevalence of anti-red blood cell antibodies in the serum and colostrum of mares and its relationship to neonatal isoerythrolysis. Am J Vet Res 1982, 43, 1917-1921.

2. Bailey E, Albright DG, Henney PJ. Equine neonatal isoerythrolysis: evidence for prevention by maternal antibodies to the Ca blood group antigen. Am J Vet Res 1988, 49, 1218-1222.

3. Becht JL. Neonatal isoerythrolysis in the foal. Part 1 : background, blood group antigens, and pathogenesis. Compend Contin Educ Pract Vet 1983, 5, S591-596.

4. Cho GJ, Yang YJ, Cho BW, Kim BH. Blood groups and antierythrocyte antibody for prevention of neonatal isoerythrolysis in horse. Korean J Vet Res 2002, 42, 469-473.

5. Cronin MT. Haemolytic disease in the new-born foal.
Vet Rec 1951, 63, 397.

6. McClure JJ. Strategies for prevention of neonatal isoerythrolysis in horses and mules. Equine Vet Educ 1997, 9, 118-122.

7. McClure JJ, Koch C, Traub-Dargatz J. Characterization of a red blood cell antigen in donkeys and mules associated with neonatal isoerythrolysis. Anim Genet 1994, 25, 119-120.

8. Nicholas FW. Introduction to veterinary genetics. pp. 165-167, Oxford University Press, New York, 1996.

9. Polkes AC, Giguére S, Lester GD, Bain FT. Factors associated with outcome in foals with neonatal isoerythrolysis (72 cases, 1988-2003). J Vet Intern Med 2008, 22, 1216-1222.

10. Scott AM, Jeffcott LB. Haemolytic disease of the newborn foal. Vet Rec 1978, 103, 71-74.

11. Stormont C. Neonatal isoerythrolysis in domestic animals: a comparative review. Adv Vet Sci Comp Med 1975, 19, 23-45.

12. Stormont C, Suzuki Y, Rhode EA. Uterine dilation in the mare. Cornell Vet 1964, 54, 439-452. 